water ${ }^{10}$. He also demonstrated (by deuterating $n$-docosane, the $n$ - $\mathrm{C}_{22} n$-paraffin) that water and pure hydrocarbons exchange hydrogen ". Thus, as Seewald suggests, the hydrocarbon-generating capacity of source rocks may increase as their kerogen incorporates hydrogen from water.

Our own data from steam pyrolysis experiments ${ }^{12}$ on organic-rich shales bear this out: $4-8$ times as much $\mathrm{CO}_{2}$ is produced during hydrocarbon generation than could possibly arise from the original oxygen content of the kerogen. The only source for this excess oxygen is water. Our measurements demonstrate that the hydrogen content of the kerogen also increases by this process. Lewan ${ }^{13}$ also noted excess $\mathrm{CO}_{2}$ production in his hydrous pyrolysis (water-bearing) experiments on oil source rocks and attributed this to oxygen from water incorporated into the kerogen.

Like Seewald, L. M. Wenger and I have seen characteristics of reversibility of organic-metamorphic reactions in our experiments. For example, increasing fluid pressure retards all aspects of organic metamorphism ${ }^{14}$. By the theory of Sato and of Helgeson and co-workers, product escape should foster reaction extent, whereas product retention should impede $\mathrm{it}^{4,5}$. Wenger and I have also observed this. Clearly there is considerable support for Seewald's data and conclusions.

Some investigators will dismiss Seewald's study as inappropriate because of the high experimental temperatures. Experiments at lower temperatures for longer times are certainly in order, but Seewald's temperatures are fairly typical of experiments simulating hydrocarbon generation in the laboratory. Furthermore, the participation of ethene in Seewald's reactions is most impressive because carbon-carbon double bond strengths are much higher than those of carbon-carbon single bonds, $145.8 \mathrm{kcal}$ $\mathrm{mol}^{-1}$ rather than $82.6 \mathrm{kcal} \mathrm{mol}^{-1}$.

The origin of the high concentrations of carboxylic acids in petroleum reservoir waters warrants comment. Most of these acids are likely to be byproducts from thermophilic sulphate-reducing bacteria slowly consuming hydrocarbons at the oil-water interface in oil reservoirs over geological time. This fact, not generally appreciated, is not academic, because these microbes have an agenda of their own apart from thermodynamic equilibrium.

The probability of hydrolytic disproportionation carries profound implications. Some are economic, and three of these stand out. First, the principal purpose of petroleum geochemical models is to aid in the discovery and commercial recovery of oil and gas. Existing models of petroleum formation do not account for either hydrolytic disproportionation or hydrogen enrichment from water and thus may fail to describe the realities of nature. Second, as Seewald points out, the initial hydrogen-to-carbon ratio of kerogen will not be an accurate measure of its ultimate hydrocarbon generation capacity if substantial amounts of hydrogen from water are incorporated into kerogen during progressive burial. Third, in hot, deepbasin conditions the hydrogen-to-carbon ratios of 'spent' kerogen are low, but the kerogen may still have significant gasgeneration capacity from incorporation of water, promoted by the high burial temperatures. So perhaps we should look upon 'spent' deep-basin kerogen as a possible gas-generating machine which has yielded much larger in-place gas resources than previously recognized.

Organic metamorphism has tended to be mathematically modelled by analyses from open-system, dry pyrolyses. This approach is particularly ill-suited to modelling natural hydrocarbon generation, which occurs in pressurized water-wet systems. Furthermore, in nature, oxygen fugacities are low and product escape is difficult because the system is closed (or semi-closed) to fluid flow, yet in these analyses product escape occurs instantly and oxygen fugacities are high. I believe a more inappropriate instrument with which to model petroleum generation could hardly be designed.

In my opinion, shared with a limited number of other researchers, petroleum formation has been trivialized by simplistic models which often simulate natural processes poorly ${ }^{15}$. One can hope, though, that other well controlled benchmark experiments like Seewald's, and those which have been suggested by Helgeson and co-workers ${ }^{4}$, will lead to realistic models.

Leigh C. Price is in the Branch of Petroleum Geology, US Geological Survey, MS-940, Denver Federal Center, Denver, Colorado 80225, USA.

1. Seewald, J. S. Nature 370, 285-287 (1994)

2. Hunt, J. M. Petroleum Geochemistry and Geology (Freeman. San Francisco, 1979)

3. Tissot, B. P. \& Welte, D. H. Petroleum Formation and Occurrence (Springer, New York, 1984)

4. Helgeson, H. C., Knox, A. M., Owens, C. E. \& Shock, E. L. Geochim. cosmochim. Acta 57, 3295-3339 (1993)

5. Sato, $M$. in Fluid-Mineral Interactions: A Tribute to H. P. Eugster (eds Spencer, R. J. \& Chou, I.-M.) 271-283 (The Geochemical Society, San Antonio, 1990).

(The Geochemical Society, San Antonio, 1990).
6. Hesp. W. \& Rigby, D. Erdoi Kohle-Erdgas 26. 70 (1973).

7. French, B. thesis, Johns Hopkins Univ. (1964).

8. Paimer. D. A. \& Drummond, S. E. Geochim. cosmochim. Acta 50. 813-823(1986).

9. Bell, J. L. S., Palmer, D. A., Barnes, H. L. \& Drummond, S. E. Geochim. cosmochim. Acta (in the press)

10. Hoering. T. Carnegie Inst. Wash. Yb. 67, $199(1968)$

11. Hoering. T. Org. Geochem. 5, 267-278(1984).

12. Wenger, L. M. \& Price, L. C. in Organic GeochemistryAdvances and Applications in Energy and the Natural Environment (ed. Manning, D. A. C.) 335-339 (1991)

13. Lewan. M. D. Am. Chem. Soc. Preprints. Division of Fue Chemistry 37, 1643--1649(1992).

14. Price, L. C. \& Wenger, L. M. Org. Geochem. 19, 141-159 (1992).

15. Price, L. C. Geochim cosmochim. Acta 57, 3261-3280 (1993).

\section{Travelling light}

MODERN optical fibre has a lower refractive index at the surface than in the centre. This keeps the beam energy away from the surface so that it cannot leak out. Daedalus is now extending this principle. He points out that if the index within the fibre declines inversely as the hyperbolic cosine of the radius, the fibre acts as a lens. Light falling on its end face is focused to a point inside it. The eyes of certain fishes seem to work this way.

Imagine, says Daedalus, an extended length of such a fibre. Parallel light falling on its end face will form an inverted image one focal length inside the fibre. But its optical odyssey will not end at that point. It will continue to travel down the fibre, being refracted by the same law as it goes. Diverging from its first focus, it will revert to parallel light two focal lengths down the fibre. At three focal lengths it will form an upright real image, and at four focal lengths it will recover the exact direction it had when it went in. The cycle will repeat indefinitely.

Thus this cunning fibre is more than a mere light-guide. It conveys not only light intensity, but image information as well. Cut to an exact multiple of four focal lengths, a bundle of such fibres will accept a pattern of light rays at one end, and emit it undeviated at the other. No matter how long and winding the bundle, it will behave like a thin, transparent window. Look into it, and you will see the scene at the other end.

Daedalus is now refining the standard process for making radially indexgraded fibre so as to produce fibre of the exact inverse 'cosh law' required. When perfected, 'Coshfibre' will have many uses, especially in remote surveillance. A simple Coshfibre bundle will do the job of an expensive TV camera and monitor, with no power supply and in any conditions of heat and pressure. Engineers will scrutinize the interiors of boilers and reactors; biologists will study burrowing mammals and deep-sea fauna; in shops, prisons, nurseries and public places, Big Brother will inspect his charges as never before.

More cunning still, Coshfibre can be made into a true cloak of invisibility. Each fibre will be woven so as to have its two ends facing outwards on opposite sides of the cloak. Light hitting one end will then travel along the fibre and emerge from the other end in exactly the same direction, as if it has gone straight through the cloak. Cover the entire surface of the garment with such windowends, wrap it totally around the wearer, and light from any direction will go right through it. The cloak and its wearer will become completely invisible.

David Jones 